\title{
La filosofía y los nacidos. ¿Por qué los filósofos olvidaron el nacimiento?
}

Francisco Díez Fischer*

\section{Resumen}

El nacimiento constituye el acontecimiento primario que da origen al hombre y en el que se generan muchas cuestiones éticas de la vida. Pero la importancia de su carácter inaugural contrasta con un aparente olvido por parte de la filosofía. Es extraño que los filósofos hayan preferido meditar más sobre el ser para la muerte, que sobre su comienzo, siendo la filosofía un saber de los orígenes. Algunos pensadores, como Stanislas Breton y Paul Ricoeur, han ensayado sus razones sobre esta inclinación tanática. Este trabajo quisiera incomodar a los filósofos en terrenos que no le son nativos y guiar los primeros pasos de una marcha a tientas que buscará la pregunta. ¿̇Hasta dónde es posible el saber filosófico del ser naciente?

\section{Palabras clave}

Nacimiento, herencia, conciencia, comienzo, lenguaje.

\footnotetext{
Doctor en Filosofía, ejerce la docencia en la Universidad Católica Argentina, se desempeña como Becario de Investigación en el CONICET y es Miembro de la Asociación Paul Ricoeur y del CLAFEN. El texto se inscribe en el marco del trabajo de investigación llevado a cabo en el área de fenomenología y hermenéutica dentro del proyecto PIP CONICET N. ${ }^{\circ}$ 5042/05 de la Academia Nacional de Ciencias de Buenos Aires y del proyecto de investigación "Rasgos fenomenológicos y hermenéuticos para una teoría de la acción. Su dimensión corporal e histórica", desarrollado en la Escuela de Humanidades de la Universidad Nacional de General San Martín (proyecto G078, 2009). Contacto: franciscodiezfischer@gmail.com.
} 


\title{
Philosophy and the born. Why philosophers forgot the birth?
}

\begin{abstract}
The birth is the primary event that originates men and will generate many bioethical issues. But the importance of its inaugural character contrasts with an apparent philosophical oblivion. It is strange that philosophers have preferred to meditate more about the being for death, than about its beginning, considering philosophy knowledge of origins. Some authors, as Stanislas Breton and Paul Ricoeur, have experimented their reasons about this tanatical inclination. This work wants to make philosophers worry about fields that are not native for them and lead the first steps in a march in the darkness that will search for questions. How far is it possible the philosophical learning of the nascent being?
\end{abstract}

\section{Keywords}

Birth, heritage, conscience, beginning, language.

La fórmula nacimiento de la filosofía es una expresión con la que se alude comúnmente a su comienzo histórico, y su referencia semántica es tan universal y bien conocida que no parece guardar secretos. Pero si nos detenemos en la estructura sintáctica de la frase y prestamos atención a la preposición "de", que une ambos términos, no encontramos una relación familiar del nacimiento con respecto a la filosofía. Pues, en verdad, el hecho de venir al mundo no es un tema que pertenezca al terreno más transitado por los filósofos.

En Occidente, la historia del pensar ha dejado en evidencia que, por alguna razón, la filosofía ha preferido meditar más sobre la muerte y la intencionalidad última de la vida hacia el final, que 
sobre su comienzo en el factum inaugural del nacimiento. Sin duda, el sabor de este gusto histórico de los filósofos se ha acentuado durante el siglo XX con las reflexiones de Heidegger sobre el ya famoso lema "ser-para-la-muerte". Pero, más allá del acento contemporáneo de la temática, podríamos sospechar si, en realidad, no existe una resistencia natural en la condición del nacimiento que le dificulta entrar en los territorios de la filosofía. O peor aún żes que la filosofía padece de algún temor o trauma estructural a ella misma que la lleva a marginar el acontecimiento del origen?

Hay que reconocer que también Heidegger -como uno de los primeros fiscales delatores de las historias de olvido que subyacen ocultas bajo los relatos filosóficos oficiales- puso en escena la tarea del recuerdo como un intento del pensamiento que quiere hacer justicia. En los últimos años, sus denuncias sobre el olvido del ser han sido acompañadas por las del olvido del lenguaje, que ha promovido la hermenéutica filosófica, y por las del olvido del mundo de la vida, contra el que ha combatido gran parte de la fenomenología contemporánea. Pues bien a tales desvelamientos podríamos añadir hoy el del olvido del nacimiento por parte de los propios denunciantes. Pero el juicio y la sentencia deberían ocurrir de tal modo que, correspondientemente con una revelación del ser, con el descubrimiento de la universalidad lingüística y la vuelta a las cosas mismas, tuviese lugar un esfuerzo filosófico por invertir el enunciado sobre su origen a fin de dar a luz una filosofía del nacimiento.

De por qué los filósofos han preferido meditar más sobre el ser para la muerte o si a la filosofía le cabe un impulso tanático estructural a todas sus formas, excede las razones que pueden estudiarse en estas páginas. Tal vez, como propone Ricoeur, la evocación del nacimiento no es familiar a los filósofos simplemente porque la muerte es más patética y porque las peores amenazas parecen venir siempre del futuro ${ }^{1}$. Lo cierto es que la preferencia pone al descubierto una

1 Paul Ricoeur, Lo voluntario y lo involuntario (Buenos Aires: Docencia, 1988), 468. 
omisión que exige la tarea histórica de subirnos a hombros de otros para esclarecer a qué se debe. Sobre el silencio filosófico en torno al nacimiento, Breton ha ensayado dos razones²:

1. El primer motivo del aparente olvido podría ser que el modelo humano sobre el que trabajan y piensan los filósofos no puede ser más que el hombre adulto, consciente y bien organizado frente al mundo, y no el recién nacido o el niño que son los protagonistas del nacimiento.

2. La referencia del adulto a la muerte tiene la ventaja de constituir una clausura del existir que satisface la demanda filosófica de un pensamiento de la totalidad, mientras que el nacimiento y la infancia, en tanto aperturas indefinidas, mortifican esta exigencia de totalización y abren horizontes de posibilidades cuya previsión y concreción escapan a cualquier sistema filosófico.

Justificado o no su olvido, si un niño se acercara al filósofo y le preguntara con inocencia de dónde viene o la razón de por qué y para qué ha nacido, no se eximiría este de tener que dar respuesta a esas preguntas que tienen su origen en el nacimiento. Frente a tan vasto territorio, poco explorado, tomaremos la guía de tres cuestiones que serán las constantes de este trabajo: 1) qué significa para nosotros comenzar, 2) qué relación une a la conciencia adulta con su propio nacimiento, y 3) hasta dónde llega a extenderse este acontecimiento inaugural en el transcurso de la vida.

\section{1. ¿Cómo se comienza a comenzar?}

En filosofía uno se decide no sólo por soluciones, sino también por la persistencia de problemas. Y el enigma de la vida que anida en el nacimiento parece ser una constante provocación hecha en dirección al pensamiento. Por eso conviene empezar con una reflexión fundamental como cuando uno quiere encontrar una palabra que pueda

2 Cf. Stanislas Breton, "L'enfant nouveau-né", en Causalité et projet (Paris: PUF, 2000), 17-44. 
durar mucho tiempo. Al igual que en esta búsqueda sabemos que si tenemos aquí la palabra es porque alguien ya la tuvo antes de nosotros; o sea que, en verdad, sólo podemos comenzar a hablar porque otros ya han comenzado. De modo semejante, venir al mundo nos engendra la duda ícómo se comienza a comenzar? Mi nacimiento es el comienzo de mi vida, el acontecimiento capital con respecto al cual dato todos los acontecimientos de mi historia, pero del que, en verdad, nunca he tenido experiencia directa consciente ni, por tanto, guardo recuerdo. Siempre estoy, por así decir, después de mi nacimiento, como en un sentido análogo digo que siempre estoy antes de mi muerte. De esta manera, como muestra Ricoeur, la primera dificultad ante la que nos encontramos para pensar nuestro propio origen es que cuando hablamos de él estamos obligados a abandonar el plano de la experiencia vivida y convertirnos en espectadores tardíos de nuestro comienzo ${ }^{3}$. Parece como si nacer nos ubicara en la situación de quien llega al teatro en el entreacto de una obra, que ya ha empezado, buscamos a oscuras nuestro sitio, y desde entonces no nos queda más remedio que seguir la marcha con tanta atención como sea posible ${ }^{4}$. Debemos resignarnos a la condición irremediable de llegar siempre tarde y nunca asistir al instante de apertura cuando levanta el telón.

Ante el hecho de nuestro propio nacimiento, toda pretensión que tengamos de nacer "por nosotros mismos" conduce al resignado reconocimiento de que no hemos sido nosotros los que hemos elegido traernos a la existencia. A pesar de todas las buenas razones para levantar quejas y reclamos ${ }^{5}$, venimos a un mundo ya comenzado y a causa de los que ya existen antes que nosotros. Así se constituye la segunda dificultad para pensar el nacimiento. Nacer expresa mi dependencia respecto a otras vidas. Mis antecesores, padres y ancestros, quisieron por mí esta existencia; o más bien, y peor aún, no la han querido exactamente; pues asumieron una responsabilidad imposible de medir que se ejerce en sotros traernos al mundo. Cf. Emil Cioran, Del inconveniente de haber nacido (Madrid: Taurus, 1981).
} 
la proximidad de potencias incalculables que mezclan combinaciones genéticas y juegos de azar, instintos y libertad. Al meditar sobre mi nacimiento descubro lo tremendo de mi situación en esa ligazón umbilical de los vivientes entre sí. Hay una filiación primaria inesperada e insuperable por la que nuestro modo humano de ser y de iniciar, incluso de pensar y de filosofar, se define como el poder comenzar en lo ya comenzado, dado por quienes han nacido antes que nosotros. Desde siempre sabemos que, bajo esa condición innegociable, se deben escribir todas las páginas de cualquier biografía.

Ahora no queda más que asumir el ejemplo en primera persona -algo mal visto por la filosofía académica-. Debo decir que de mis ancestros donatarios no sólo he recibido el comienzo de mi vida, que permanece para mí siempre inaccesible, sino también el capital de una herencia que representa la tercera dificultad para pensar con objetividad el nacimiento. Los que me han hecho entrar en la comunidad de pertenencia, me han dejado inscripto y ligado a una larga cadena de generaciones pasadas y futuras ${ }^{6}$. Pero lo han hecho a tal punto que mi situación natal me invita a confiar en una conversación histórico-universal que siempre me supera y parece hacer de mí solo un producto parcial y finito de un legado inmenso y muy antiguo. En verdad, desconozco hasta qué punto mi existencia individual, aparentemente única e irrepetible, está gravada por mis antepasados con una herencia de la que, por otra parte, no estoy seguro que no sea una hipoteca. Es cierto que "sólo porque ya estamos en medio de una historia podemos comenzar a contar nuestra propia historia"7; pero más allá del grado de tragedia y de comedia en el que venimos al mundo, queda claro que si hay algo que, en verdad, no somos es hojas en blanco. A partir del primer aliento, incluso desde los primerísimos estadios de la noche intrauterina, cada vida está marcada por las huellas de una alquimia incalculable. La fuerza oculta de la señala que los romanos "empleaban las expresiones 'vivir' y 'estar entre los hombres' (inter homines esse) o 'morir' y 'cesar de estar entre hombres' (inter homines esse desinere) como sinónimos." 22. 
herencia hace que el nacimiento nunca quede sumido totalmente en el pasado, pues su patrimonio es omnipresente y está tatuado en cada cuerpo antes del lenguaje. Algo tan intemporal como el inconsciente y tan difícil de educar como los instintos.

En síntesis, respecto de nuestro comienzo hay tres dificultades que parecen obligar a renunciar a una consideración objetiva del nacimiento como desearía la filosofía:

1. No podemos tener un sentido objetivo de la idea de comienzo a causa de esa extraña paradoja por la que, si solo a la subjetividad puede aplicarse la idea de comienzo en tanto él se dice de algo único e irrepetible; al mismo tiempo, ese comienzo jamás puede ser directamente experimentado por ella misma, pues siempre comienza en lo ya comenzado.

2. La filiación y dependencia de otros, que se hace evidente en el nacimiento, obliga a explicar el comienzo de mi ser de un modo alienante a través de los que son mi ascendencia. La objetividad sucumbe, entonces, ante el vértigo de las combinaciones incalculables de las que dependo y por las que he venido al mundo tal como soy.

3. La tremenda dimensión histórica y fuerza genética que tiene esta herencia amplía la escala con la que pensamos el problema y enfoca a ese individuo único e irrepetible desde la perspectiva de la especie como un resultado y efecto suyo: "el flujo de la especie rueda por debajo de mí y yo no soy más que una aparición fugitiva en su superficie"8.

Todas estas dificultades hacen que cuando hablamos del nacimiento debamos ejercer una filosofía sin objetividad o en los límites de las posibilidades del saber objetivo que, como dice Ricoeur, es, en cierto sentido, el fracaso de ese saber. Y si lo que pensemos de ahora en más muestra que el nacimiento es inaccesible a todas las formas 
de autoconciencia, tendremos razones suficientes para excusar de cargo y culpa a la filosofía, pues es natural e inevitable el olvido por el que la hemos denunciado ante los tribunales de la historia.

\section{La condición inaccesible de venir al mundo}

Ahora más atentos a la dimensión del problema, volvemos sobre la primera dificultad: nuestro nacimiento es un comienzo en lo ya comenzado del que no podemos tener una experiencia directa ni un saber objetivo. Sin duda, no es sencillo para la conciencia adulta, educada en la objetividad y en la experimentación, tener que enfrentar una insuperable inconciencia respecto de su comienzo. ¿̇ué le significa esta relación paradójica con su principio? Abordemos la segunda guía del trabajo siguiendo por un momento una vieja metáfora ${ }^{9}$. Imaginemos un libro, pero no cualquiera de ellos, sino uno tan particular como el que Borges describe en su cuento El libro de arena. El relato comienza con un hombre que una tarde recibe en su casa la visita inesperada de un vendedor de Biblias, de apariencia extraña y gris, le ofrece un libro sagrado cuyas páginas no tienen principio ni fin.

Me pidió que buscara la primera hoja.

Apoyé la mano izquierda sobre la portada y abrí con el dedo pulgar casi pegado al índice. Todo fue inútil: siempre se interponían varias hojas entre la portada y la mano. Era como si brotaran del libro. Ahora busque el final.

También fracasé; apenas logré balbucear con una voz que no era la mía:

Esto no puede ser.

Siempre en voz baja el vendedor de Biblias me dijo:

- No puede ser pero es. El número de páginas de este libro es exactamente infinito. Ninguna es la primera; ninguna es la última. No sé por qué están numeradas de ese modo arbitrario.

9 Seguimos aquí el esfuerzo que hace Sloterdijk, sirviéndose de esta metáfora literaria, bajo el presupuesto de que "el libro representa en el mundo una de las singularidades más gratas que pueden corresponder a una totalidad". Peter Sloterdijk, op. cit., 39. 
Acaso para dar a entender que los términos de una serie infinita admiten cualquier número ${ }^{10}$.

El libro de arena es un libro incontable porque como la arena no tiene principio ni fin ${ }^{11}$. Su contenido no respeta la cronología primaria de la numeración que permite la continuidad de la lectura de una página a la siguiente; por eso, tal como narra el cuento, el primer poseedor sólo podía ser analfabeto. Únicamente inconsciente de su "tesoro" podía cargar con semejante infinito literario. En cambio, se vuelve insufrible para el hombre educado y lector consciente que termina por abandonarlo en algún anaquel de la Biblioteca Nacional, luego de largas noches de insomnio, obsesionado por su contenido infinito. Según las consideraciones previas de Breton y Ricoeur, un libro así sería sin duda antifilosófico porque irritaría de tal manera la exigencia de totalización y objetividad del pensamiento que lo llevaría como al protagonista del cuento a rozar la demencia (y esa es siempre una razón suficiente para un sano olvido y ocultamiento).

¿Qué sucede si acercamos la estructura de este extraño libro a la relación entre la conciencia adulta y el nacimiento? Toda vida "empieza con la concepción o el nacimiento y termina con la muerte. Este sería, por tanto, si queremos seguir con la misma imagen, un libro finito, del mismo modo que las biografías humanas son historias que pueden ser leídas al final y hojeadas de principio a fin"12. Sin embargo, exigir a un hombre viviente leer la última página de su historia suena absurdo y cínico, pues significa plantear al aún vivo la fantasmagórica tarea de pensarse a sí mismo como algo ya muerto y cerrar de golpe el libro de su vida. En cambio, si intentamos abrir la primera página para leer en voz alta lo que está ahí, enseguida se verá cuán excesiva es la exigencia. La invitación a pasar a la primera página de nuestra propia existencia cae en el ámbito de lo inadmisible. La conciencia adulta, del mismo modo que el personaje del

10 Jorge Luis Borges, "El libro de arena", en Obras Completas III (Barcelona: Emecé, 1996), 69.

11 Remito al análisis que Guillermo Martínez hace sobre la numeración de las páginas y el carácter misterioso de este libro. Cf. G. Martínez, Borges y la matemática (Buenos Aires: Eudeba, 2005). 
relato, no puede llegar hasta las primeras hojas de su propia historia. Parece haber una extraña y curiosa estructura literaria en el mundo de la vida por la que todas las páginas de las biografías se escriben sobre comienzos inaccesibles a la lectura.

Sin embargo, el nacimiento sin hacerse accesible se deja ver como el más acá de la conciencia necesaria para toda experiencia, pues observamos que la condición de "ser nacido" se manifiesta permanentemente como el horizonte de todas las posibilidades. El nacimiento se da como el acontecimiento posibilitante del mundo, aunque no pueda haber de él una experiencia directa. La estructura vinculante de esta condición de expropiación que sufrimos con respecto a la condición de posibilidad inicial parece determinar casi todas las formas de autoconciencia. Toda conciencia adulta es nacida. Se erige sobre el factum inconsciente del parto por el cual otro la trae al mundo. La estructura parece repetirse en otros comienzos suyos que son también, por así decir, a mitad de camino: el de la memoria con los primeros recuerdos y el de la narración en el aprendizaje de la lengua. Son ejemplos de formas desarrolladas y conscientes de vincularse con ese ensombrecido hecho del nacimiento. ¿Qué significa para el ser capaz de narrar y para el poder de su lenguaje, que él mismo no pueda alcanzar a su vez en primera persona su propio venir al mundo?

\subsection{La conciencia de un recuerdo imposible}

Desde la perspectiva de nuestra memoria, el nacimiento es una de esas incómodas ausencias presentes en su faltar, pues "por raro que pueda sonar, esta historia mía empieza con mi ausencia o, dicho más prudentemente, con la ausencia de mi recuerdo y bajo la pérdida de mi conciencia de haber estado presente"13. Aunque yo, como héroe de mi historia, exija haber estado de alguna manera para dar fe de mi visita en este mundo, todo nacimiento da siempre la impresión 
de ser tratado "de una forma tan grosera y desmemoriada por su propia conciencia que parecería que ustedes son un don nadie que tras venir del Sur una noche atraviesan furtivamente y sin papeles la frontera" ${ }^{14}$ hacia la existencia. La conciencia no da ceremonias de recibimiento ni levanta monumentos en el lugar de la entrada de su protagonista. Para ella, el viaje por el que se traspasa el umbral tuvo, tiene y tendrá lugar en la oscuridad ${ }^{15}$. Carga con esa incomodidad de la memoria de no poder llegar hasta su comienzo y de tener que edificar y sostener toda su historia sobre un suelo "inmemorial" para sí misma. La condición de posibilidad del recuerdo es precisamente aquello "tan antiguo, que no hay memoria de cuándo empezó"16. Inmemorial es nuestro propio nacimiento que la memoria de otros narra para nosotros. Pues no sólo llegamos al mundo con la obra ya empezada y con la ayuda de acomodadores, sino que, en lo que respecta a nuestros primeros momentos en la escena del mundo, también somos mudos espectadores. Desde el primer instante de vida, en el útero materno y aún en las primeras hojas de la infancia, los recuerdos de otros son los que escriben el principio de nuestra historia con tatuajes de un color imborrable que cuentan, como dice Agustín de Hipona, "aquella edad que no recuerdo haber vivido y sobre la cual he creído a otros"17. El fenómeno de una vida que se comprende a sí misma tiene, entonces, no sólo el problema de la laguna y oscuridad de su comienzo, sino, sobre todo, el problema de que, lo que puede saber de él, debe alimentarse de historias que ha oído contar a familiares. Folletines retrospectivos que, de alguna manera, encubren ese horror vacui de que justo en el momento de su entrada en la escena de la existencia, la noche del estreno, el sujeto que dice "yo" aún no estaba presente.

14 Ibíd., 62

15 Que el parto no sea agradable y quiera ser oculto, es algo que recuerda otras experiencias inaugurales. Del mismo modo que el cuerpo sólo vea la luz luego de grandes esfuerzos, no es la excepción, sino una suerte de regla vital.

16 Definición de "inmemorial" del Diccionario de la Real Academia Española, 22. ${ }^{a}$ Edición (Madrid: Espasa Calpe, 2001).

17 San Agustín, Confesiones, Edición crítica y anotada por el padre Ángel Custodio Vega. 5. ${ }^{a}$ edición (Madrid: BAC, 1968), I, 7, 12. 


\subsection{El lenguaje sobre el nacimiento}

Para el hombre, en cuanto ser finito que habla, el comienzo del ser y el del lenguaje no van de la mano en ninguna circunstancia. En las primeras páginas de nuestro libro biográfico, queda claro que "cuando comienza el lenguaje, el ser ya está ahí presente; y cuando se quiere empezar con el ser, uno se hunde en el agujero negro de la ausencia de palabra"18. Este defasaje que acompaña al recuerdo muestra que, si el hombre es animal narrador por antonomasia, es porque también es la criatura condenada a hacerse cargo de sí, sólo desde el momento en que accede al lenguaje. Antes de la narración consciente, solo hay la noche infantil y lo dado a la luz en ella, el caos de lo sin nombre, el agujero de nuestro venir al mundo, que más tarde taponamos con relatos, porque, en verdad, somos las extrañas criaturas que no disponen de su comienzo. Aquí reposa el origen de los cuentos que los adultos se cuentan a sí mismos sobre esa silenciosa y femenina oscuridad intrauterina, previa a que la gramática forme las relaciones entre lo existente. La historia de la conciencia parece consistir en hacer de ese primer soplo un verbo, sin dejar de reconocer en la extrañeza del nacimiento lo extranjero que cada hombre es de sí mismo desde que comienza a contarse su venir a la presencia, el inicio del mundo en el que se encontró viviendo.

No obstante, como dice Mugica, donde termina el lenguaje no empieza necesariamente lo indecible ${ }^{19}$. Del mismo modo que ante lo inmemorial, a veces comienza una revelación que escapa a la objetividad. Ensayemos que, por un momento, pudiéramos regresar a nuestro comienzo real, ¿̇qué pasaría? Estamos ante nuestro propio nacimiento, la primera oscuridad se abre de nuevo ino se revelaría la falta de límites de ese momento inicial? "Pero sobre todo ocurriría esto: me atravesarían de nuevo las agujas de la realidad para dibujarme con la terrible tinta de la identidad y otra vez se acercaría el

19 Hugo Mugica, Lo naciente. Pensar el acto creador (Madrid: Pretextos, 2007), 75-106. 
hierro ardiente a mi piel para marcarme las propiedades reconocibles y grabarme los signos de separación a prueba de falsificación entre los omóplatos" ${ }^{20}$. El nacimiento pertenece y se ubica en los márgenes inaccesibles del cuerpo oscuro que soy yo mismo, y esa naturaleza oculta, que la conciencia experimenta en el lenguaje y en la memoria, parece revelarse de manera privilegiada en la frente, pues "lo que más lejos quiere ocultarse de nosotros se inscribió en los individuos entre los omóplatos"21.

La figura de la frente encarna las características peculiares del inconsciente. Es la parte del cuerpo que no puede verse nunca a sí misma y la que siempre se vuelve a los otros. Es el ejemplo paradigmático de esa extraña situación en la que nada puede ser más público que lo que es para mí invisible (indecible e inmemorable) pero que, al mismo tiempo, "se caracteriza por no poder no delatarse"22. No deja de ser curioso que en el nacimiento la frente sea lo primero que venga a la luz y que, en ritos iniciáticos como el bautismo, sea el lugar donde se deja la marca del segundo nacimiento. Reiterando las cualidades reveladoras de la frente, el nacimiento es el acontecimiento inalcanzable para nosotros, pero accesible a los demás, que inaugura nuestra entrada en la arena pública de la existencia.

\section{La filiación y la herencia: nacer al mundo público}

El vínculo paradójico de la conciencia adulta con el nacimiento nos ha puesto frente a la dimensión pública de venir al mundo donde se juegan las otras dos dificultades señaladas por Ricoeur para pensar el nacimiento: la dependencia de otros y la herencia como forma de explicar la venida al mundo desde la condición de pertenencia. Como hecho fundador de otras tantas experiencias inaugurales que nos ofrecen a la luz, el nacimiento es como dice Arendt "el aconte-

20 Peter Sloterdijk, op. cit., 52.
21 Ibíd., 28.

22 Ídem. 
cimiento fundamental de la ontología política"23. Podemos enumerar tres líneas de justificación fundamentales:

1. Porque otorga una nacionalidad, es decir, que sella el vínculo del nacido con su tierra y lo inscribe en la larga cadena comunitaria de sus ancestros, contemporáneos y sucesores. En este sentido, Arendt afirma que la natalidad es parte de la condición más general de la existencia humana ${ }^{24}$ y tiene que desembocar casi inevitablemente en la fijación dentro de una nacionalidad. Por eso utilizamos la expresión lingüística de "nacer-dentro" [hineingeboren] de una sociedad. A su entender, todas las asociaciones sociales que descansan sobre este principio pueden ser consideradas "naciones", es decir, lugares de nacimiento ${ }^{25}$.

2. El nacimiento establece una dirección de fundación entre lo público y lo privado. Si recorremos las observaciones de Arendt, la esfera privada como primera condición para la admisión en la esfera pública y en la completa ciudadanía empieza por el nacimiento. Venir al mundo es un acontecimiento relacional que funda lo público desde lo oculto de lo privado. Antes de la Edad Moderna, todas las civilizaciones se sostenían sobre el carácter sagrado de la propiedad privada ${ }^{26}$. Y "lo sagrado de lo privado era como lo sagrado de lo oculto, es decir, del nacimiento y de la muerte, comienzo y fin de los mortales que, al igual que todas las criaturas vivas, surgían y retornaban a la oscuridad de un submundo"27. La esfera familiar privada era y sigue siendo originalmente la esfera del nacer y del morir, que debe

Arendt se asombra de la "provocadora franqueza" que existe en las lenguas occidentales cuando, para referirnos a la adquisición de una condición de pertenencia estatal en una nación huésped, hablamos de "naturalización" que no es otra cosa que "natalizaciones" artificiales.

"En sus orígenes, la propiedad significaba ni más ni menos el tener un sitio de uno en alguna parte concreta del mundo y por lo tanto pertenecer al cuerpo político, es decir, ser la cabeza de una de las familias que juntas formaban la esfera pública. Este sitio del mundo privadamente poseído era tan exactamente al de la familia que lo poseía, que la expulsión de un ciudadano no sólo podía significar la confiscación de su hacienda sino también la destrucción real del propio edificio". Ibíd., 70. Ibíd., 70-71. 
ocultarse de la esfera pública porque acoge los acontecimientos impenetrables al saber humano objetivo. "Ocultas precisamente porque el hombre adulto no sabe de dónde procede cuando nace ni adónde va cuando muere"28, y es sabido que la incomodidad de la ignorancia anima el olvido. Si bien la condición de nacido es común a todos, el nacimiento se mantiene en secreto por ser escándalo para la conciencia adulta. Forma parte de los misterios reveladores que escapan a su capacidad de narración y de las experiencias más allá del discurso que eran antiguamente no políticas o quizás antipolíticas por definición.

3. La condición natal de lo político queda manifiesta en la relación entre nacimiento y lenguaje. Más allá de la distancia o de la incapacidad humana de alcanzar lingüísticamente el instante de su nacimiento, la lengua que nos es más próxima es siempre la de la comunidad en la que venimos al mundo.

Si la vida y el lenguaje se transmiten fundamentalmente en los grupos de natalidad -y es difícil figurarse cómo podría ser esto de otro modo-, entonces en principio no se puede esperar de los hombres que crecen dentro de sus lenguas nacionales otra cosa que la capacidad de hablar sus lenguas nacionales en todos sus aspectos... ${ }^{29}$.

El nacimiento nos liga a ese continuum histórico y lingüístico en el que los lenguajes son legados a los nuevos hablantes como la jerga especializada del sistema dentro del que viven y se educan. Los hombres vienen al mundo en el interior de esas grandes cavernas simbólicas habitables que llamamos lenguaje. Pero dado que "están condenados de principio a comenzar sometiéndose de lleno a las condiciones de transmisión de la vida existente antes de ellos, es legítimo plantear al transmisor de la lengua la exigencia, quizá exagerada, de considerar una política de la no-proliferación también en lo concerniente a la violencia ligada al lenguaje y su miseria hecha palabra"30. El vínculo filial de mutua pertenencia liga a los hombres a 
venir al mundo en comunidades lingüísticas que siguen hablando el discurso del odio contra los que hablan diferente (v. gr. los bárbaros). Y esa violencia parece ser más encarnizada contra aquello sobre lo que no puede hablarse o que queda fuera de su alcance. Como acontecimiento primario pero inasible, el nacimiento es blanco de ataques lingüísticos que toman formas diversas, por ejemplo, la negación de darle palabra a la violencia ejercida contra él en el ámbito público.

Como acontecimiento privado que abre el umbral comunitario, el nacimiento transforma la filiación de la conciencia para dejar de ser una explicación alienante de nuestro ser y convertirse en el modo de comprender nuestra condición de pertenencia: "ser engendrado", "salido de". Nacer expresa esa ligazón originaria más allá de la causalidad que tiene un testigo corporal imborrable: el ombligo. En la conciencia adulta dormita la conciencia umbilical que guarda esa marca de dependencia y adherencia corporal a los antecesores. Por eso la infancia no debe ser despreciada por el filósofo en vistas a una mayoría de edad; porque muestra que "deber el ser" (y no "el deber ser") sostiene la autonomía y el saber objetivo de la conciencia. La infancia no es sólo pueril. Toda conciencia es infantil porque lleva la cicatriz que designa, a la vez, la lesión del nacimiento y la sutura que mantiene unido a los padres con un vínculo no arbitrario. Aquí, como propone Ricoeur, el testimonio para la filosofía es doble: la infancia y el inconsciente. La in-ciencia del inconsciente que prologa nuestra infancia es un testimonio valioso para el filósofo que está a la búsqueda de las raíces y las vinculaciones, pues la relación de filiación es el modo en que quedo unido a mi herencia. De esta manera, deja de ser una hipoteca histórica, el terror abismal y la inquietud de la vida tras de mí; aunque siga siendo cierto que toda historia resume una prehistoria y que la amplitud de esta prehistoria engendra el temor de la impotencia de iniciativa de mi conciencia. Sin embargo, en tanto estamos unidos a ella por filiación no es el peso de una naturaleza extraña, sino que se vuelve el capital recibido de 
otro, pero el capital que "soy yo mismo dado por otro a mí mismo"31. A la filosofía se le abre la posibilidad de pensar la historia en mí, una tarea que le quedaría bien a la hermenéutica, pues mi herencia no es más que mi inconsciente puesto fuera de mí y mi ascendencia es otro nombre para el comienzo de mi existencia.

\section{El oscuro aparecer del nacimiento}

Hasta aquí las dimensiones del nacimiento se han ampliado más allá de lo sospechado. Pero si hemos de dar a luz a una filosofía del nacimiento, cabe aún dar un paso más y alcanzar la tercera y última cuestión, planteada en las primeras páginas de este trabajo: ¿̇hasta dónde se extiende el carácter fundante del nacimiento? ¿Cuál es el alcance ontológico de ser nacido? Si, como hemos sugerido, el hecho de nacer se asemeja en algo a la frente, podemos decir que ser nacido se caracteriza por no poder no delatarse. Claro que se muestra como ausencia, como ese olvido del principio que funda, perdura y se revela durante la totalidad de la vida. La huida de mi nacimiento que escapa al poder de mi recuerdo y de mi lenguaje es precisamente el rasgo más característico de esta experiencia posibilitante (si es posible llamar experiencia a esa falta consciente de experiencia). La "experiencia" de mi nacimiento es rica en su pobreza misma y ese es el carácter de límite que nos impone como propio. El silencio de mi memoria al término de mis recuerdos, que cada vez se hacen más enigmáticos y espaciados, no equivale a una experiencia del nacimiento; pues una nada de recuerdo no es el recuerdo de un comienzo. Pero ese silencio atestigua que la huida de mi origen no es ilimitada. El hecho de nacer es el término presentido como límite inferior de la conciencia que, a la vez, la posibilita. Sin embargo, ¿qué es lo que posibilita el nacimiento en su constante aparecer?

El nacimiento humano podría ser como un relámpago que brilla bruscamente en aquellas primeras páginas inaccesibles, y por lo tanto 
olvidadas, del libro de una vida. Imaginemos que nuestra entrada al mundo se produce en la oscura clandestinidad al modo de un rayo que cruza el cielo. ¿Qué vemos?

Si durante una tormenta nocturna se abre el cielo y durante un segundo un relámpago hace temblar el paisaje, comprobamos cómo poco después no existe oscuridad más profunda. El relámpago del nacimiento, en cambio, sigue estando en cierta medida en el cielo, e incluso a la larga se confunde con el mismo cielo; de ahí que uno se acostumbre a creer que hay claridad (...) pero en el fondo sólo hay claridad porque el relámpago del nacimiento no ha cesado de iluminar y porque él, aunque se torne invisible e imperceptible, contribuye a que todo lo visible alcance visibilidad. El relámpago del nacimiento es así el claro o calvero [Lichtung] en el que se mueven todos aquellos que llegan al mundo ${ }^{32}$.

Tal vez, tendríamos que seguir la precisión imaginativa de Zambrano y distinguir "entre lo que se presenta como claro y lo que en su palpitar oscuro crea claridad"33. Tal como el centro oscuro de la llama que ilumina, y hace ver todo lo que ilumina, el nacimiento es el rayo del origen que tiene ese brillo oscuro que lo oculta a la conciencia adulta. Su poder es escenográfico. Como la constante oscuridad de un escenario, el hueco olvidado del origen se hace presente a lo largo de la vida como el trueno de ese rayo invisible que tuvo lugar en el comienzo. Su relampaguear se produce en la noche fértil del útero y posee la extrañísima propiedad de no extinguirse una vez que ha brillado. Es la apertura por la que tiembla la existencia con nuestra entrada en el mundo y que permanece oculta hasta que el "trueno natalicio que llega después es capaz de sacudirnos y hacernos despertar de la costumbre de vivir bajo la luz del relámpago duraderamente invisible. Truena ocasionalmente en la conciencia cuando irrumpen los acontecimientos que se asemejan al acontecimiento fundamental"34. No es un trueno que sólo se oye proveniente de una lejanía pasada sino un trueno que aún conserva su fuego y enciende revelando a la conciencia las incomparables turbulencias de la tormenta primaria. La sensibilidad para esta meteorología natal debería ser una actitud

Peter Sloterdijk, op. cit., 66.

María Zambrano, Senderos (Barcelona: Editorial Anthropos, 1986), 15.

Peter Sloterdijk, op. cit., 66. 
filosófica que nos recordara capaces de continuar temblando al oír su trueno y de comprender que, a pesar del brillo imperceptible de su oscuridad, su entonces sigue siendo todavía.

\section{Ser nacido: el constante parir de la conciencia}

Si es oportuno decir que aún nacemos o mantenemos una condición de nacientes, queda por ver qué acontece cuando se produce este rayo y pensar qué de él puede durar. Luego del tiempo de la concepción, el nacimiento también representa un vínculo que queda suspendido. Cuando el parto ha tenido lugar, el seno de la madre vuelve a ser ligero y libre. En cambio, el niño que parecía estar libre y ligero en el cuerpo materno, ahora empieza a sentir el peso de la carne y la ligazón al mundo. Pero el parto como desligamiento del nacido de la madre tiene para este también un aspecto liberador, puesto que durante la fase inminente al nacimiento se cumple un des-asfixiarse del estrecho pasaje del final perinatal. Por eso, en lo concerniente al que llega al mundo, la palabra "parto" recibe un significado positivo. Su definición como "hacer salir a la luz o al público lo que estaba oculto o ignorado" refiere a ese des-asfixiarse y des-estrecharse del factum del final que inaugura el principio. Es la primera vez que el nacido accede al aire. Para él brilla el primer resplandor de la libertad externa y se abre ese claro que es el rayo ontológico de desligamiento y revelación por antonomasia ${ }^{35}$.

Si bien en el momento del parto cuando el niño se desliga de la madre acontece la ligazón de la nueva vida al mundo, también es cierto que, para el recién llegado, tras su éxodo del cuerpo materno, no existe exactamente un mundo en el sentido más estricto de la expresión al que uno pueda "vincularse". En el dolor del parto, el niño traído al

35 Una de las condiciones de posibilidad de que los seres humanos se conduzcan hacia un mundo común, es "el desligamiento en el parto de todo individuo singular de la comunión fetal con la madre. Sólo después de esta 'cimentación' en comunión y tras su consiguiente explosión puede haber en algún momento algo así como una comunicación, pero no como un primer presupuesto, sino como un resultado posterior". Ibíd., 103. 
"mundo" no cae de pleno en otro escenario, sino que "mundo" es sólo una expresión que entra en juego más tarde como compendio de los contenidos de la apertura en la que tras el parto quedamos desligados. La tesis acerca de su situación inicial en el mundo tiene que reformularse: esta sucede en el apego del niño a lo abierto de un escenario, a lo imprevisible, a lo incierto. Nacer es rasgar el mundo, abrirse a la apertura en la que nos encontramos viviendo, que no tiene por qué ni para qué, porque lo abierto es precisamente lo infundado. Acaso por qué o para qué hemos nacido, ¿̇no son las primeras preguntas infantiles que incomodan a la conciencia durante toda la vida, tan inquietantes por el grado de indeterminación que abren? Las páginas de posibilidades que aparecen con cada nacimiento son incalculables, aún para quienes nos reciben y conocen la historia que nos antecede y a la que pertenecemos. Por eso el apego a los cuentos de relleno, correspondientes con el olvido estructural del nacimiento, se forja ante el telón de fondo del miedo abierto al venir al mundo; un temor que parece volver a abrirse en acontecimientos inaugurales semejantes.

Si tomamos las observaciones de Arendt, lo que caracteriza al nacimiento es ser initium, que se repite con cada palabra y cada acto, en tanto que por ellos "nos insertamos en el mundo humano, y esta inserción es como un segundo nacimiento, en el que confirmamos y asumimos el hecho desnudo de nuestra original apariencia física"36. El impulso primario del lenguaje, de la narración y de la acción surge de ese rayo primero, ese aliento en el que respiramos por primera vez y nos adentramos al mundo cuando nacemos. Que, a la vez, volvemos a presentificar en la permanencia de su luz y apertura al comenzar algo nuevo. Por eso actuar, en su sentido más general, significa para Arendt tomar una iniciativa: crear $^{37}$. En la propia naturaleza del co-

36 Hannah Arendt, op. cit., 201.

37 "Debido a que son initium los recién llegados y principiantes, por virtud del nacimiento, los hombres toman la iniciativa, se prestan a la acción". Y este comienzo no es el mismo que el del mundo como principium. "Con la creación del hombre, el principio del comienzo entró en el propio mundo, que, claro está, no es más que otra forma de decir que el principio de la libertad se creó al crearse al hombre, no antes", Ibíd., 201. 
mienzo, como rayo del initium, se inicia algo nuevo que no puede esperarse de cualquier cosa que haya ocurrido antes. "Este carácter de lo pasmoso inesperado es inherente a todos los comienzos y a todos los orígenes" ${ }^{\prime 38}$, incluso forma parte esencial de lo deslumbrante del rayo en la oscuridad de la tormenta. Pero ìhasta qué punto esa propiedad forma parte del nacimiento si siempre comenzamos en lo ya comenzado? Pues bien, "lo nuevo siempre se da en oposición a las abrumadoras desigualdades de las leyes estadísticas y de su probabilidad, que para todos los fines prácticos y cotidianos son certeza; por lo tanto, lo nuevo siempre aparece en forma de milagro"39. Que cada hombre sea aún naciente significa que cabe esperarse de él lo inesperado, que puede realizar lo incalculable, aunque proceda de un linaje tan antiguo. "Y una vez más esto es posible debido sólo a que cada hombre es único, de tal manera que con cada nacimiento algo singularmente nuevo entra en el mundo. Con respecto a este alguien que es único cabe decir verdaderamente que nadie estuvo allí antes que él" ${ }^{40}$. Venir al mundo es darse ese irrepetible instante sobre un viejo suelo de pertenencia en el que se escucha el milagro de "sólo una vez", ante el cual el gris visitante del cuento de Borges vuelve a repetir en voz baja: "No puede ser, pero es".

\section{Conclusión}

El nacimiento coloca a la filosofía ante la exigencia de dar respuesta a la pregunta inicial, planteada a todo recién llegado, la que inaugura la vida y perdura hasta su muerte: ¿̇uién eres tú? Si debiéramos pensar un lugar del cuerpo para que quede inscripta esta pregunta, apuntaríamos nuevamente a la frente; pues "el 'quién', que se presenta tan claro e inconfundible a los demás, permanece oculto para la propia persona"41, y esa condición, que se inscribe en 
el momento del nacimiento, escapa como duda al saber filosófico. Entre las palabras y los actos del nacido se generan imprevisibles respuestas. Si hasta "el acto más pequeño en las circunstancias más limitadas lleva la simiente de la misma ilimitación, ya que un acto y a veces una palabra, basta para cambiar cualquier constelación" ${ }^{42}$, más aún el nacimiento como acontecimiento relacional primario porta la simiente de la ilimitación, fuerza las fronteras y corta esquemas. Por él se hace evidente que una forma de lo abierto viene al mundo trayendo nuevos pero inciertos posibles. No se extiende en la irrealidad, ni se repite en la circularidad, se centra en la intensidad del quién eres. Esta intensidad es el modo de la constante presencia del engendramiento que rompe el ritmo de la repetición, quiebra la sumatoria e instaura lo incomparable. Por eso, "sin la articulación de la natalidad, estaríamos condenados a girar para siempre en el repetido ciclo del llegar a ser, sin la facultad para deshacer lo que hemos hecho y controlar al menos parcialmente los procesos que hemos desencadenado, seríamos las víctimas de una automática necesidad con todos los signos de las leyes inexorables" ${ }^{\prime 4}$.

La facultad de interrumpir y comenzar algo nuevo viene desde el pasado aún vigente y operante del nacimiento. Por lo cual, parir es algo inherente a la acción y al lenguaje "a manera de recordatorio siempre presente de que los hombres, aunque han de morir, no han nacido para eso sino para comenzar"44. El milagro de lo nuevo, de nacer otra vez escuchando el trueno de la vez primera, es posible sólo por el simple hecho de ser nacido. Lo abierto del nacimiento se mantiene brillando oculto para hacer del ser un ser constantemente naciente. Si bien la filosofía ha puesto en evidencia con su olvido que la conciencia adulta no llega hasta el instante inicial, ni dispone de él, encuentra que desde él parte cada vez y ese permanente partir parece ser la posibilidad de su estar. 


\section{Bibliografía}

Diccionario de la Real Academia Española. Edición 22. Madrid: Espasa Calpe, 2001.

Arendt, H. La condición humana. Traducido por Ramón Gil Novales. Buenos Aires: Paidós, 1993.

Borges, J. L. "El libro de arena". En Obras Completas III. Barcelona: Emecé, 1996.

Breton, S. Causalité et projet. Paris: PUF, 2000.

Cioran, E. Del inconveniente de haber nacido. Traducido por Esther Seligson. Madrid: Taurus, 1981.

Martínez, G. Borges y la matemática. Buenos Aires: Eudeba, 2005.

Mugica, H. Lo naciente. Pensar el acto creador. Madrid: Pretextos, 2007.

Ricoeur, P. Lo voluntario y lo involuntario. Vol. II. Traducido por Juan Carlos Gorlier. Buenos Aires: Docencia, 1988.

San Agustín. Confesiones. Edición crítica y anotada por el Padre Ángel Custodio Vega. 5. ${ }^{\mathrm{a}}$ edición. Madrid: BAC, 1968.

Sloterdijk, P. Venir al mundo, venir al lenguaje. Traducido por Germán Cano. Valencia: Pre-textos, 2006.

Zambrano, M. Senderos. Barcelona: Editorial Anthropos, 1986. 